\title{
Effects of habitat and livestock on nest productivity of the Asian houbara Chlamydotis macqueenii in Bukhara Province, Uzbekistan
}

\author{
Maxim Koshkin $^{1} \cdot$ Robert J. Burnside ${ }^{1} \cdot$ Charlotte E. Packman $^{1} \cdot$ Nigel J. Collar ${ }^{2}$. \\ Paul M. Dolman ${ }^{1}$
}

Received: 17 September 2015 /Revised: 10 April 2016 / Accepted: 26 April 2016/Published online: 7 May 2016

(C) The Author(s) 2016. This article is published with open access at Springerlink.com

\begin{abstract}
To inform population support measures for the unsustainably hunted Asian houbara Chlamydotis macqueenii (IUCN Vulnerable), we examined potential habitat and landuse effects on nest productivity in the Kyzylkum Desert, Uzbekistan. We monitored 177 nests across different semiarid shrub assemblages (clay-sand and salinity gradients) and a range of livestock densities $\left(0-80 \mathrm{~km}^{-2}\right)$. Nest success (mean $51.4 \%$, $95 \%$ CI 42.4-60.4\%) was similar across 4 years; predation caused $85 \%$ of those failures for which the cause was known, and only three nests were trampled by livestock. Nesting begins within a few weeks of arrival when food appears scarce, but later nests were more likely to fail owing to the emergence of a key predator, suggesting that foraging conditions on wintering and passage sites may be important for nest productivity. Nest success was similar across three shrub assemblages and was unrelated to landscape rugosity, shrub frequency or livestock density but was greater with taller mean shrub height (range 13-67 cm) within $50 \mathrm{~m}$. Clutch size (mean $=3.2$ eggs) and per-egg hatchability in successful nests $(87.5 \%)$ did not differ with laying date, shrub assemblage or livestock density. We therefore found no evidence that livestock density reduced nest productivity across the range examined, while differing shrub assemblages appeared to offer similar habitat quality. Asian houbara appear
\end{abstract}

Electronic supplementary material The online version of this article (doi:10.1007/s10344-016-1018-9) contains supplementary material, which is available to authorized users.

Maxim Koshkin

makoshkin@gmail.com

1 School of Environmental Sciences, University of East Anglia, Norwich Research Park, Norwich, Norfolk NR4 7TJ, UK

2 BirdLife International, Pembroke Street, Cambridge CB2 3QZ, UK well-adapted to a range of semi-desert habitats and tolerate moderate disturbance by pastoralism. No obvious in situ mitigation measures arise from these findings, leaving regulation and control as the key requirement to render hunting sustainable.

Keywords Buffer effect $\cdot$ Exploited population $\cdot$ Nest success $\cdot$ Hatchability $\cdot$ Pastoralism

\section{Introduction}

The Asian houbara Chlamydotis macqueenii (IUCN status Vulnerable: BirdLife International 2015), a bustard of desert and semi-arid landscapes, is the chief quarry of Arab falconers. Asian houbara have suffered near extirpation of resident populations in the Arabian Peninsula and major declines across Central Asia, primarily as a consequence of unregulated hunting and trapping during migration and winter (BirdLife International 2014; Riou et al. 2011; Tourenq et al. 2005), with degradation of breeding habitat considered a further factor (Lavee 1988). To date, the primary conservation response to this circumstance has been to release increasingly large numbers of captive-bred individuals of both Asian and African houbara Chlamydotis undulata to re-establish or reinforce exploited populations (Chargé et al. 2014; Hardouin et al. 2015; Islam et al. 2012). Population supplementation by releases of captive-bred stock may play an important role in houbara conservation (Combreau et al. 2005), but captive breeding also incurs certain genetic, disease, temperament and domestication risks (Dolman et al. 2015; Frankham 2008; Snyder et al. 1996; Williams and Hoffman 2009). For houbara, selection in captivity has been reported on a range of physiological, reproductive and behavioural traits (Chargé et al. 2014), but the consequences for reinforced populations 
are unknown. As repeated industrial-scale reinforcement has the potential to compromise the integrity of populations, supplementation should seek to minimise impacts, both by maintaining the highest possible integrity of releases (Combreau et al. 2005) and through management to minimise the relative numbers required to be released (Burnside et al. 2016). To assist in this, opportunities for alternative in situ conservation measures clearly need to be explored. Here, we examine whether there may be conservation interventions to improve the breeding productivity of free-living populations, to reduce the scale of supplementation.

For species breeding across heterogeneous environments, an understanding of the potential demographic effects of landuse and landscape composition can help identify areas that determine regional-scale demography (Dolman 2012; Waber et al. 2013). Asian houbara (hereafter 'houbara') breed across a wide range of landscapes and vegetation types, varying with drainage, landform and substrate, from consolidated sands to clay saltpans (Gubin 2004), and differing in shrub height and composition (Koshkin et al. 2014, 2016). Nest success of wild houbara has been quantified (Combreau and Launay 1999; Combreau et al. 2002; Lavee 1988) and nest micro-site selection investigated (Aghanajafizadeh et al. 2012; Yang et al. 2003), but whether productivity varies with habitat differences or livestock levels remains unknown. Rangelands occupy most houbara breeding habitat in Central Asia (Robinson et al. 2007), with obvious potential to impact populations through habitat modification, livestock trampling and disturbance of nests. However, as livestock is vital to local livelihoods and regional economies (Gintzburger et al. 2003; Kerven et al. 2006), robust evidence of its effects on houbara is needed before any management intervention is decided. In Israel, expert opinion has suggested that livestock grazing negatively impacts nest success through disturbance (Lavee 1988), and in Morocco, livestock concentrations may restrict African houbara access to suitable areas (Le Cuziat et al. 2005b). In Morocco and Fuerteventura, breeding African houbaras avoid major roads, human settlements and sheep camps (Carrascal et al. 2008; Hingrat et al. 2008; Le Cuziat et al. 2005a), but whether productivity is influenced by these anthropogenic factors has not been examined. Although the numbers and distribution of male houbara showed no response to low and moderate sheep densities in the southern Kyzylkum, Uzbekistan (Koshkin et al. 2014, 2016), livestock impacts on nesting are unknown.

Using data from 177 Asian houbara nests monitored in the Kyzylkum over 4 years (2012-2015), we (i) quantify clutch size, nest success and hatchability (which together determine nest productivity), and their variation within the breeding season and across years; (ii) test for the effects of land use and habitat on these components of nest productivity, particularly the influences of shrub species composition and of sheep density; and (iii) assess the causes of nest failure. We undertook this work to explore whether our findings could have significant implications for appropriate long-term houbara conservation, extending management options beyond the current strategy of high-volume captive-bred releases.

\section{Methods}

\section{Study area and population}

The study area $\left(39.34-40.56^{\circ} \mathrm{N} 62.21-65.20^{\circ} \mathrm{E}\right)$ covers $14,300 \mathrm{~km}^{2}$ of predominantly flat houbara habitat, comprising drought-resistant and halophytic shrub vegetation, in the southern Kyzylkum Desert, Bukhara Province, Uzbekistan. Grazing by mixed flocks of sheep and goats (hereafter 'sheep', as these dominate) is limited by the distribution of functioning wells, major roads and trackways used for water transportation (Koshkin et al. 2014). Large areas of desert, particularly with limited accessibility to water, are grazed only in spring during lambing, when sheep exploit ephemeral graminoids (Carex physodes and Bromus spp.). From mid-May, after the main houbara nesting period is complete, sheep are withdrawn to villages, agricultural areas or permanent water sources. Owing to the short duration of pastoralism and absence of winter browsing, sheep have limited impact on shrub vegetation (Koshkin et al. 2014), but extensive grazing of mobile flocks may potentially disrupt nesting houbara. Although areas closer to settlements and permanent water sources, with higher densities of wells and camps, support larger numbers of sheep, much of the surrounding desert is under-utilised (Koshkin et al. 2014). This spatial variation in sheep density allowed livestock effects to be examined.

Since 2011, under licence from the Uzbekistan government, the Emirates Bird Breeding Center for Conservation (EBBCC) has released modest numbers of captive-bred houbara (all carrying metal rings) in the Bukhara Province of the Kyzylkum Desert. Moreover, over the period of our study, some releases have occurred in the neighbouring Navoiy Province of Uzbekistan (BirdLife International 2014), while others have taken place in southern Kazakhstan, culminating in large-scale releases in 2014 (WAM 2014). Consequently, captive-bred released birds may be present and nest in the study area, with the potential to confound the interpretation of habitat effects on nesting success if their captive experience were to result in differential breeding performance. We therefore excluded nests of known captive-bred released birds (including those monitored by satellite telemetry) from the current study, but not all incubating females in our study were checked for metal rings (which, to the best of our knowledge, all captive-bred birds released in 
Central Asia carry). From the 177 nests monitored, 97 were confirmed (by catching, nest cameras or were of PTT-tagged wild birds) to be from wild females. Although the origin of 80 nests was not confirmed, we judge the proportion of captivebred birds among these to be negligible for four reasons.

- First, in a random sample of 62 nests (with identity confirmed by catching, $n=29$, or nest cameras, $n=33$, excluding nests found by PTT tracking), only one captive-bred ringed bird (of EBBCC origin) was found. From this, we estimate the proportion of released captive-bred birds among the remaining females of undetermined origin to be very low (mean $1.6 \%, 95 \%$ CI $0.2-10.5 \%$, thus between 0 and 8 captive-bred females are expected among the 80 undetermined nests).

- Second, independent evidence indicates that the relative density of captive-bred individuals in the Bukhara breeding population is likely to be low. To date, $<280$ birds a year have been released by EBBCC in our study area, annually representing some $7.5 \%$ of the extant population (1886 males and presumably a similar number of females: Koshkin et al. 2016). These birds were either 1-year-olds released in spring or 4-month-olds released in August; few 1 -year-old females and none of the males would have bred in the year of release, and both they and the August releases then experienced high over-winter mortality such that only $10.8 \%$ returned to the breeding grounds the following year (Burnside et al. 2016). Thus, adult female recruits may have numbered fewer than 15-20 per year.

- Third, released birds exhibit strong site fidelity: maximum natal dispersal distance of 9 satellite-tracked captive-bred birds that survived to complete their first return migration (see Burnside et al. 2016) was $51.1 \mathrm{~km}$, median $27.4 \mathrm{~km}$, upper quartile $36.3 \mathrm{~km}$ (RJB, unpublished data). Thus, while birds of EBBCC origin may recruit into our study population if they survive, locally sourced stock released in Navoiy (breeding centre approximately $150 \mathrm{~km}$ from the centre of our study area) or Kazakhstan (country border at least $250 \mathrm{~km}$ away) are very unlikely to do so.

- Fourth, as the number of released birds recruited into the free living population should be cumulative with time, reinforcement of the breeding population would have been low at the start of our study as releases had occurred for 1 year in Bukhara and possibly 2 years in Navoiy and Kazakhstan (L. Hardouin, in litt.), and by 2015, the female identity was checked for virtually all (56/61) nests.

Therefore, while we readily acknowledge that our study population has been supplemented by captive-bred birds, we have no evidence to indicate that a significant reinforcement of the wild breeding population has occurred, and we are entirely confident that these supplementary birds have exerted negligible confounding influence on our results.

\section{Nest searching and monitoring}

Houbara nests were located between 20 March (all years) and 30 April (2012) or 10 May (2013, 2014 and 2015) by searching for female tracks; searches between 11:00 and 15:00 were excluded to avoid risk to eggs through exposure to high temperatures. Searches traversed a variety of substrates (consolidated and weakly consolidated sand, clay) across five shrub assemblages (see below); cultivated areas and drifting dunes were excluded, as they hold very low densities of houbara during the breeding season (Koshkin et al. 2014). Although search effort was widely distributed, the probability of finding nests through tracking was greater in sandy areas; searches on clay were possible only when they held scattered drifts of sand. Thus, the distribution of nests monitored did not represent relative nesting density across habitats, and therefore we do not infer habitat preferences. Nevertheless, environmental determinants of productivity per nesting attempt could be examined, as sufficient nests were located in each habitat. An additional 46 nests were located by tracking 25 wild females carrying satellite transmitters (30 g PTT-100 Argos/GPS solarpowered; Microwave Telemetry Inc.) caught using lines of leg snares, set around initial nests found during standard fieldwork. As catching of females was considered likely to cause nest desertion, or at least prolonged exposure of the eggs, these females were caught early in the season to maximise their chances of re-nesting, and their clutches were removed for artificial incubation at EBBCC's breeding centre; this terminated monitoring of the initial nesting attempt. Subsequent nests of these females (in the same and successive years) were visited under standard protocols.

We found 177 nests (excluding one additional nest subsequently found to be of a captive-bred released female), of which 20, 44, 52 and 61 were found in 2012, 2013, 2014 and 2015, respectively (Fig. 1). The 25 wild females tracked by satellite telemetry each contributed more than one nest to the data (total 71). Ten nests were found outside the area sampled for vegetation and sheep density (with outcome and/or clutch size unknown for six of these) and were therefore excluded from analyses of environmental effects. Three nests where females were flushed by car were also excluded from analyses of nest success, as these were considered to have been compromised (all were predated within 1 day). Of the remaining sample of 164, 64 were found in Astragalus, 19 in Salsola rigida, 78 in Salsola arbuscula and only three in Artemisia shrub vegetation. Nests found in Artemisia were excluded from models that included 'shrub assemblage' owing to low sample size. This provided 161 nests for modelling of environmental effects, or 164 where analyses included MDS2 instead of 'shrub assemblage' (see below), with sample sizes for differing life history stages of clutch size 
Fig. 1 Distribution of Asian houbara nests across a gradient of sheep density monitored during 4 years of study within nest extent area $\left(2231 \mathrm{~km}^{2}\right)$ in the southern Kyzylkum Desert, Uzbekistan (excluding nests outside the sampled territory and three nests found in Artemisia shrub assemblage)

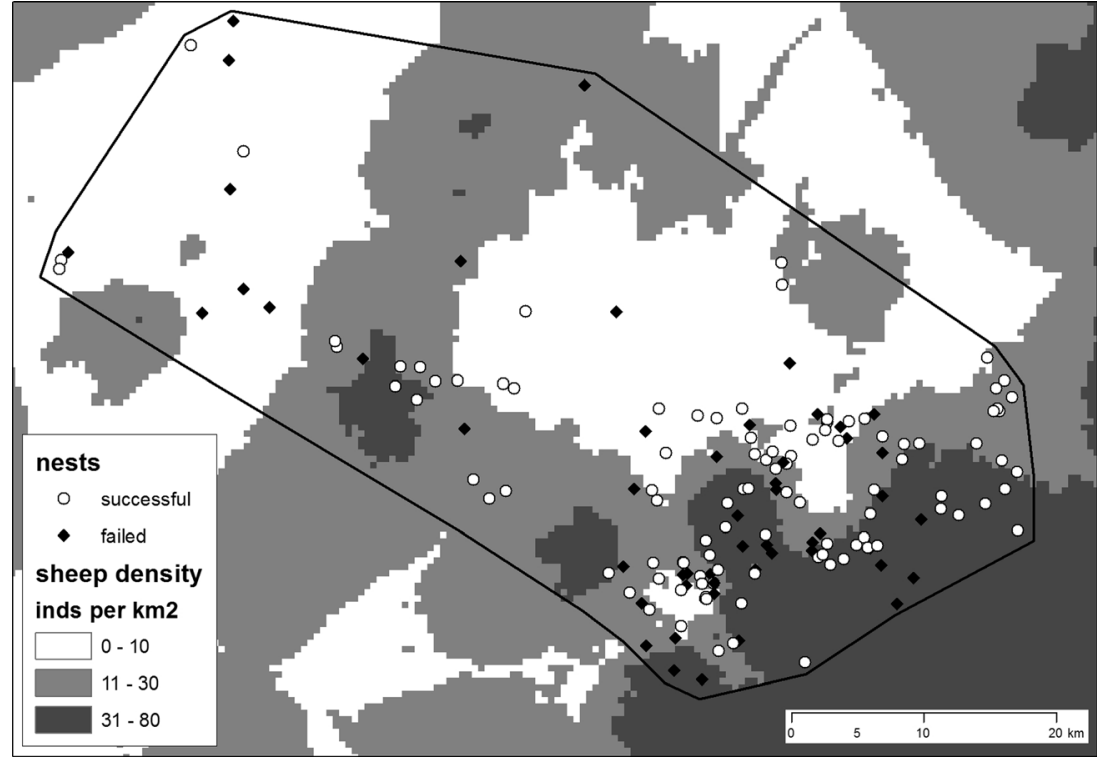

( $n=159$ or 162 , respectively), nest success ( $n=151$ or 154$)$ and hatchability ( $n=68$ or 71$)$.

In 2012, eggs were not measured, and laying date was estimated from hatching date and duration of incubation (23 days: Combreau et al. 2002) with a range of uncertainty for nests that failed, following Mallord et al. (2007). In 20132015, hatching and thus laying dates were predicted from egg dimensions and weight (measured at the time the nest was found) following the weight loss equation from Hoyt (1979), using species-specific weight coefficient $K_{\mathrm{W}}=0.00055$ and assuming linear weight loss of $17.4 \%$ across incubation, following Combreau et al. (2002). After finding, subsequent monitoring visits were made at intervals of 5 or 6 days, and then 2 days before and 1 day after the predicted hatching date. As it is important to minimise cues that may influence the ability of predators to detect nests, at the first visit (when eggs were measured and weighed), fieldworkers did not kneel at the nest and left using the same route, which was swept (using local vegetation) to remove all footprints. On all subsequent visits prior to completion or failure, observations were made remotely through binoculars and at no time did fieldworkers approach closer than $10 \mathrm{~m}$. For further details of nest monitoring, see Online resources (Section 2).

Nest outcome was inferred through signs within and around the nest scrape. A nest was considered failed if it was found empty prior to the predicted hatching date or with signs of predation or trampling, and successful if at least one egg hatched, based on signs of a successful outcome (Online resources, Section 3). In 2014 and 2015, nest cameras and temperature loggers were used in a total of 36 nests to confirm outcomes inferred from field signs and to refine estimated completion date (Online resources, Section 3). Nest cameras, equipped with infra-red $(940 \mathrm{~nm})$ emitting diodes for night surveillance, were set to record video continuously; to reduce disturbance, cameras were deployed during the second visit to a nest at a distance of $>1 \mathrm{~m}$ from the scrape, with installation taking $<20 \mathrm{~min}$. Battery units were buried approximately $10 \mathrm{~m}$ from the nest to reduce disturbance during maintenance visits (every 5 days). Temperature loggers (I-buttons, DS1921G-F5 thermochrons) capable of recording temperature every $15 \mathrm{~s}$ over the incubation period were placed in nests at first finding and left until after completion of the nesting attempt, with one in substrate $1 \mathrm{~cm}$ beneath the eggs and a second at the same depth some $30 \mathrm{~cm}$ from the scrape to record ambient temperature, so that times of incubation could be determined. When a nest had no logger or camera and exact day of finishing was unknown, the mid-point between the final and penultimate visit was taken as the end date (Mayfield 1975).

\section{Habitat and land-use variables}

Six candidate habitat and land-use variables were examined for their potential influence on clutch size, hatchability and nest success (Table 1). Structure and composition of shrub vegetation in the vicinity of the nest were recorded along four $50 \mathrm{~m}$ cardinally directed line intercepts radiating from the scrape, to represent habitat at the scale of nest-site placement within the home range. Along each line intercept, the species and height (to $1 \mathrm{~cm}$ ) of each shrub touching the line was recorded following Koshkin et al. (2014), pooling data for each nest (hereafter 'composite samples'). Mean shrub height (measure of vegetation structure) and square-root transformed shrub frequency (an index of vegetation cover per composite 200-m sample) were calculated across 19 shrub species (excluding the dwarf species Salsola gemmascens and Nanophyton erinaceum with mean height $<12 \mathrm{~cm}$ ). To avoid disturbance, vegetation measurements were taken after nest outcomes were known. 
Table 1 Candidate habitat and land-use variables for models of nest success, clutch size and hatchability

\begin{tabular}{|c|c|c|}
\hline Variable name & Description & Type of data \\
\hline \multicolumn{3}{|l|}{ A priori covariates } \\
\hline Date & $\begin{array}{l}\text { Day of the season (date }=1 \text { is the earliest monitoring day of across all years), } \\
\text { automatically incorporated into the required fields of the encounter history. } \\
\text { Each day is } 1 \text { encounter occasion }\end{array}$ & Continuous \\
\hline Incubation day & Incubation day (1-23) of a nest on any given day of monitoring & Continuous \\
\hline Year & Year of the study (2012-2015) & Categorical \\
\hline Laydate & First egg laying date, coded as Julian date, enumerated from 1 January for each year & Continuous \\
\hline \multicolumn{3}{|l|}{ Land-use variables } \\
\hline Sheep density & $\begin{array}{l}\text { Mean density (inds. } \mathrm{km}^{-2} \text { ) extracted for 1-km radius buffers around nests from } \\
\text { interpolated surface based on 4-year data }\left(\text { low }=0-10 \text { individuals } \mathrm{km}^{-2} \text {, }\right. \\
\left.\text { medium }=11-30 \mathrm{~km}^{-2} \text {, high }=31-80 \mathrm{~km}^{-2}\right)\end{array}$ & Continuous \\
\hline \multicolumn{3}{|l|}{ Habitat variables } \\
\hline Shrub height & Mean shrub height $(\mathrm{cm})(n=19$ species $)$ within $50 \mathrm{~m}$ & Continuous \\
\hline Shrub frequency & Total number of shrubs per composite sample ( $n=19$ species) & Continuous \\
\hline Vegetation MDS1 & Nest-specific sample score from MDS analysis & Continuous \\
\hline Vegetation MDS2 & Nest-specific sample score from MDS analysis & Continuous \\
\hline Shrub assemblage & Three shrub assemblages & Categorical \\
\hline Topo. rugosity & Standard deviation of elevation $(\mathrm{m})$ per $30-\mathrm{m}$ pixel within $100-\mathrm{m}$ radius & \\
\hline
\end{tabular}

Potential effects of shrub composition were considered, separately examining continual measures and categorical 'assemblages'. Local shrub species composition was summarised by two orthogonal ordination variables (vegetation MDS1 and vegetation MDS2), provided by multidimensional scaling analysis (MDS) of the covariance matrix of composite shrub frequency data per sampling location $(n=871)$. Landscape-scale distribution of shrub assemblages (shrub assemblage) across the study area was classified and mapped, considering the eight most abundant shrub species (63.2\% of all shrubs measured) using composite samples obtained from nests $(n=167)$ and an additional 704 sampling locations during May-June 2012, 2013 and 2014, with over 69,000 shrubs identified and recorded. Cluster analysis was performed on the Bray-Curtis similarity matrix of shrub frequencies (square-rooted), using average-linkage clustering and a $50 \%$ similarity level to select the most widespread assemblages (which classified $87 \%$ of all samples): (a) 'Artemisia' on gypseous/clay soils, dominated by Artemisia diffusa (2873 $\left.\mathrm{km}^{2}\right)$; (b) 'S. rigida' on halophytic soils, dominated by Salsola rigida and $S$. gemmascens $\left(2180 \mathrm{~km}^{2}\right)$; (c) 'S. arbuscula' on gypseous and halophytic soils, dominated by $S$. arbuscula, with high density of $A$. diffusa and $S$. rigida (3904 km²); (d) 'Astragalus' on semi-consolidated sands, dominated by Astragalus villosissimus and Convolvulus hamadae, also containing Salsola spp. $\left(3778 \mathrm{~km}^{2}\right)$. A fifth, (e) 'Calligonum', on drifting or weakly consolidated sands and typified by Calligonum and Salsola spp. (1603 km²), was excluded from further consideration as no nests were found in this assemblage despite searches. Ordination and cluster analyses were performed in PRIMER 6.1.10 (Clarke 1993; Peet and Roberts 2013).

Topographic rugosity (topo. rugosity) was measured as the standard deviation of elevation within 100-m radius around nests (extracted from ASTER GDEM V2, 30-m horizontal resolution, 1-m vertical resolution).

Sheep were counted along $11,470 \mathrm{~km}$ of distance transects during 2012-2015, comprising 141 ten-kilometre off-road transects (with some repeated 2-3 times; total distance $3500 \mathrm{~km}$ ) driven in March-May 2012, and 1594 fivekilometre transects each driven once along trackways or infrequently used roads in March-May 2013, 2014 and 2015. Average sampling intensity was $0.8 \mathrm{~km}$ transect per $\mathrm{km}^{2}$ but relatively greater in higher sheep density areas, in order to capture local variability in distribution and density of sheep camps, and lower in remote areas with homogeneous low livestock density (Online resources, Fig. ESM5). For each sheep flock observed (total $n=938$ ), the number of individuals (mean group size 159.9, $\mathrm{SD} \pm 134.7$, range 2-750) and distance to flock centre (measured by laser range finder) were recorded. Preliminary year-specific distance analysis, with transect-specific sheep densities (allocated to transect centroids) interpolated to a density surface, showed that spatial distribution of livestock was strongly correlated and thus stable between years (Online resources, Section 4; Table ESM2), as expected from the stable pattern of camp occupancy. We therefore created a composite sheep density surface (Fig. 1) by inverse distance-weighted averaging across all 4 years of transect-specific density estimates $(n=1735)$. In high to medium sheep density areas (within $20 \mathrm{~km}$ of the irrigation and 
settlement boundary), mean distance between camps proved to be $2.3 \mathrm{~km}(\mathrm{SD}=1.2)$; the close packing of sheep camps relative to greater sheep flock home ranges $(\approx 5 \mathrm{~km}$ around camps and wells; MK, personal observations) suggests that grazing territories overlapped with all intervening desert subjected to grazing. We are therefore confident that interpolation of local sheep density measures is not obscuring or 'oversmoothing' local variation between grazed and undisturbed territories.

\section{Modelling effects of habitat and land-use on clutch size, nest success and hatchability}

Clutch size and hatchability (number of eggs hatching within successful nests of known clutch size, with clutch size as an offset scaled with parameter 1.0) were examined using generalised linear models (GLMs) with Poisson error. Nest survival models were constructed in MARK (v 6.2), using the RMark package (Laake 2013) in R 3.1.1 (R Core Team 2013). Unlike the Mayfield method (Mayfield 1961) or its extension to logistic multivariate models (Aebischer 1999), modelling in RMark allows daily nest survival rate (dsr) to vary both with season and across incubation (Dinsmore et al. 2002). Mean probability of nest success per attempt, from the start of incubation to hatching (23 days), was estimated in RMark as the product of daily nest survival rates. Nests were considered as independent observations, since failure was considered to be largely stochastic (rather than related to female quality) and most were from different individuals. Laying dates are represented by Julian dates, enumerated from 1 January.

Nest success, clutch size and hatchability were a priori expected to vary among years, depending on conditions both in the wintering areas (carry-over effect) and on the breeding grounds (e.g. variations in food availability, temperature and predator abundance). Additionally, the likelihood of nest failure may change during the season (owing to increasing temperature and predator emergence) and with nest age (owing to accumulating female tracks and scent in later incubation or changes in duration or frequency of absences from the nest). Therefore, for nest success potential effects of year, season (date) and its quadratic term $\left(\right.$ date $\left.^{2}\right)$ and incubation day were examined with GLMs inspecting change in AIC on variable removal. For clutch size and hatchability, potential effects of year, laydate and its quadratic term (laydate + laydate $^{2}$ ) were examined with similar GLMs. Strongly supported covariates (for which $\Delta$ AIC $>+2.0$ on removal) were retained and forced into subsequent analysis of habitat and land-use effects (Table 1) in an information theoretic multi-model inference (MMI) framework, averaging across the full candidate model set (Burnham and Anderson 2002).

All candidate habitat and land-use variables were tested for inter-correlation (using either Pearson's or ANOVA) prior to modelling. Vegetation MDS1 was related to both shrub assemblage (ANOVA, $F_{2,148}=14.1, p=0.001 ; R^{2}=0.14$ ) and shrub height (Pearson's $r=0.52$ ). As shrub height received stronger support in univariate GLMs of nest success (on variable removal, $\triangle \mathrm{AIC}=5.1$ ) than vegetation MDS1 $(\triangle \mathrm{AIC}=-1.9)$, the latter was excluded from subsequent analyses. However, vegetation MDS2 (a continuous measure of shrub composition) was unrelated to shrub height (Pearson's $r=-0.07$ ) and so was included in model sets with this measure of vegetation structure. Lastly, categorical shrub assemblage was examined in an alternative model set that did not include vegetation structure, as it was correlated with shrub height (ANOVA, $F_{2,148}=25.1, p=0.001 ; R^{2}=0.24$ ).

Monitoring nests using nest cameras may potentially bias overall nest success and information on the relative importance of predator species, as cameras may affect species-specific predation rates (Richardson et al. 2009). Camera deployment on nests was opportunistic, often not spanning the entire nest monitoring period. Therefore, to test for any potential influence of nest cameras on nest survival, exposure days for nests monitored in 2014 and 2015 (years in which cameras were used) were partitioned between days with and without camera, coding days preceding camera deployment as successful, running univariate models in MARK, controlling for year and inspecting $\triangle \mathrm{AIC}$ on variable removal.

MMI was applied to all models using the MuMIn package in R (Barton 2013) to estimate model-averaged coefficients and unconditional standard errors accounting for the Akaike weight of each candidate model (Burnham and Anderson 2002). The apparent degree of support for effects may be inflated by reliance on relative variable importance (RVI) (the sum of Akaike weights of all models in which the variable occurs) when there are many competing models (Boughey et al. 2011). Therefore, we also examined the $95 \%$ null interval of the probability distribution of RVI for a random variable $($ mean $=1, \mathrm{SD}=1)$ across $1000 \mathrm{MMI}$ iterations, following Boughey et al. (2011). Support for a predictor was further assessed by inspecting the $95 \%$ unconditional confidence intervals of averaged parameter coefficients. Effects were considered strongly supported when model-averaged parameter estimates lay beyond the $95 \%$ null interval and $95 \%$ parameter CIs did not span zero. Data were not over-dispersed, as the ratio of residual deviance to residual degrees of freedom (Crawley 2007) was $<1.0$ for all three full models.

\section{Results}

\section{Temporal and spatial distribution of nests}

Earliest laying dates varied among years (range 14-24 March) with the latest clutch initiated on 15 May in 2015; however, the median laying date was remarkably consistent for 3 years 
(2, 1 and 2 April, for 2012, 2013 and 2014, respectively), although slightly later (8 April) in 2015. For 10 satellitetagged females, 15 first nesting attempts were started a mean of 12.6 (range 8-20) days after arrival in the breeding area. Females started laying only after daily minimum temperatures consistently exceeded $0{ }^{\circ} \mathrm{C}$, and laying generally ceased once maximum daily temperatures consistently exceeded $25{ }^{\circ} \mathrm{C}$ (usually in early May; see Online resources, Fig. ESM1).

Nests were mainly found in areas dominated by semiconsolidated and loose sand owing to greater ease of tracking. Consequently, only 16 nests $(9.0 \%$ of all nests) were found within areas dominated by clay substrates (over $75 \%$ clay coverage, estimated over four replicate $2 \mathrm{~m} \times 2 \mathrm{~m}$ quadrats placed $50 \mathrm{~m}$ from the nest) (Supplementary materials, Fig. ESM4), involving either satellite-tagged females (nine nests), flushing a female near a nest (two nests), watching a female return to a nest (one nest) or tracking (four nests).

Of those nests in the core study area for which livestock density was mapped, most were found in areas with medium $(n=69)$ density, with fewer in areas of high $(n=45)$ or low $(n=41)$ density. Relative to area, fewer nests were found in areas of low livestock density $\left(\chi_{3}^{2}=12.3, p=0.01\right)$ (Online resources, Fig. ESM2), probably owing to reduced search effort in remote areas. Nests were located within vegetation of varying shrub frequency (mean $\pm \mathrm{SD}=64.2 \pm 28.8$ shrubs/ $200 \mathrm{~m}$, range $=15-151)$ and height $($ mean $\pm \mathrm{SD}=31.2$ $\pm 8.1 \mathrm{~cm}$, range $=12.7-67.3)$.

\section{Clutch size}

Preliminary GLMs showed no support for effects on clutch size of season (removal of laydate ${ }^{2}$ and then laydate: $\Delta \mathrm{AIC}=-1.7$ and -0.8 , respectively) or year $(\Delta \mathrm{AIC}=-3.4)$, so neither laydate nor year was included in MMI. Clutch size was not affected by any habitat or land-use variables (Fig. 2a). Here we present results for MMI that incorporated vegetation MDS2 and shrub height (both continuous); however, similar results were obtained with an alternative set of models that considered the categorical variable shrub assemblage. Clutch size (mean $\pm \mathrm{SD}=3.2 \pm 0.6$ eggs; range $2-5$ ) was similar among areas with different sheep density (low, mean $\pm \mathrm{SE}=3.4 \pm 0.1$ eggs; medium, $3.3 \pm 0.1$ eggs; high, $3.1 \pm 0.1$ eggs; $\triangle A I C=-1.8)$ and shrub assemblages $(S$. rigida, mean $\pm \mathrm{SE}=3.0 \pm 0.1 \mathrm{eggs} ; S$. arbuscula, mean $\pm \mathrm{SE}=3.3 \pm 0.1$ eggs; Astragalus, mean $\pm \mathrm{SE}=3.2 \pm 0.1$ eggs; $\Delta \mathrm{AIC}=-2.6$ ). Egg volume decreased by approximately $5 \%$ (change between first and last date quartiles as $\%$ of mean) with laydate $(\beta=0.0003, \mathrm{SE} \pm 0.00007 ; \Delta \mathrm{AIC}=5.0 ; \mathrm{GLMM}$ with gamma error, controlling for nest ID as random effect) but did not differ between years ( $\triangle \mathrm{AIC}=-3.0$; GLMM with gamma error, nest ID as random effect).

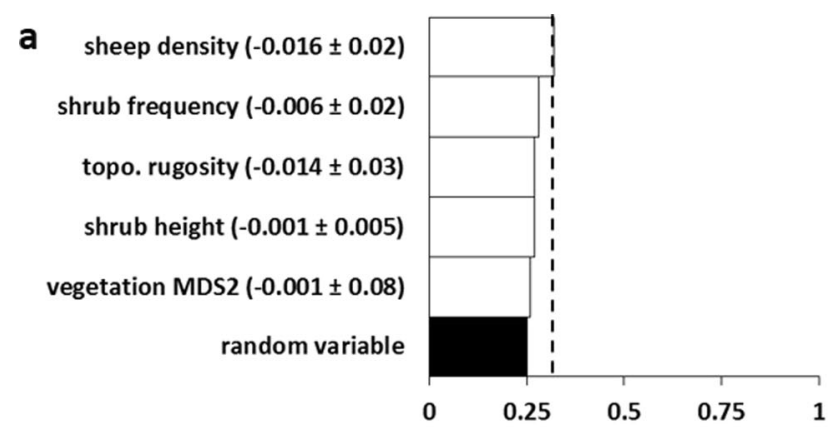

b

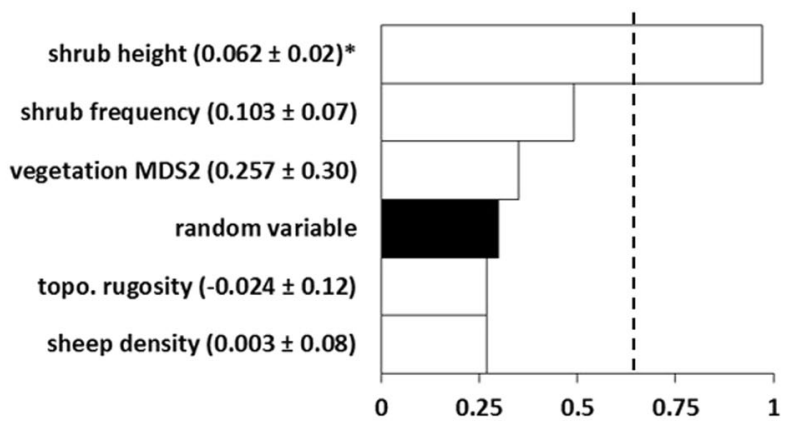

C

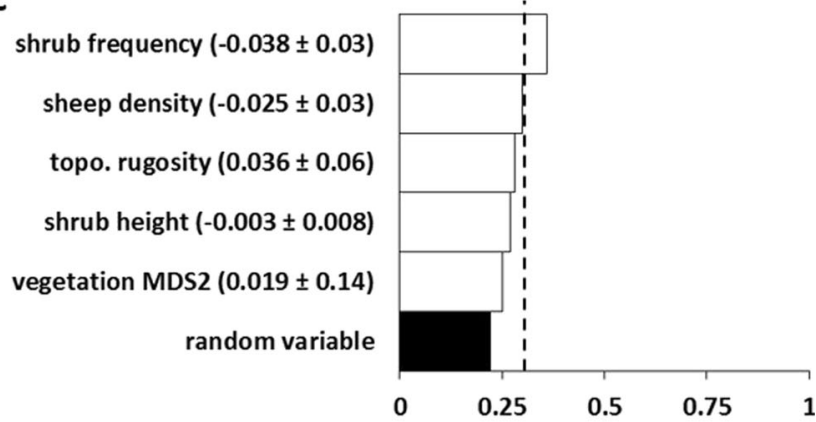

Relative variable importance

Fig. 2 Relative variable importance (RVI: sum of AIC weights) and model-averaged coefficient \pm unconditional SE of predictors (in parentheses) from multi-model inference of a clutch size, $\mathbf{b}$ nesting success and $\mathbf{c}$ hatchability (the proportion of eggs hatching within a successful nest) of Asian houbara Chlamydotis macqueenii in the Kyzylkum Desert, Uzbekistan. Parameter estimates for individual levels within categorical variables (shrub assemblage and year) are not shown. Asterisk $(*)$ denotes strongly supported predictors (averaged parameter estimate CIs not spanning zero and RVI beyond $95 \%$ null limit). For each set of models, the median RVI (filled box) and upper $95 \%$ null limit (dashed line) of a randomly generated predictor are shown (see text for details)

\section{Nest success}

Nest success was estimated from 163 nests with 1913 exposure days, excluding 14 nests with unknown outcome or zero exposure days (found at hatching or at predation). Mean nest success across 4 years was $51.4 \%$ (95\% CI 42.4-60.4\%). There was no evidence of any effect of nest camera on dsr $(\triangle \mathrm{AIC}=-1.7$ on variable removal), with similar rates for nests with $(97.7 \% ; n=35$ nests; 429 exposure days) and without cameras $(97.0 \% ; n=61$ nests; 683 exposure days). 
Further, a priori modelling showed that daily survival rate did not vary between years (Fig. 3) and did not decline with incubation day $(\triangle \mathrm{AIC}=-2.0$ and -1.8 on removal of year and incubation day, respectively). However, there was strong support for a quadratic relationship between nest success and day of season $\left(\Delta \mathrm{AIC}=2.4\right.$ and 0.7 on removal of date $^{2}$ and then date, respectively), with higher survival early in the season (1st week mean $\pm \mathrm{SE}=74.9 \pm 7.0 \%$ ), decreasing by around $50 \%$ by 4 th week (mean $\pm \mathrm{SE}=37.1 \pm 7.0 \%$ ) and then slightly increasing towards the end (6th week mean $\pm \mathrm{SE}=44.7$ $\pm 14.1 \%$ ) (Fig. 4); therefore, date + date $^{2}$ were forced into MMI. Modelling of solely the first 3 years again supported the linear effect of date ( $\triangle \mathrm{AIC}=2.1$ on variable removal), but the quadratic effect of date $^{2}$ on daily nest survival was only important when nests from 2015 were included in the analysis, potentially owing to an extended season and later nests in that year.

For 59 nests that failed, the cause of failure could be attributed to $48(81 \%)$ (Table 2). Predation represented $85 \%$ of failures for which the cause was known, with the predator responsible identified or inferred in $73 \%$ of predated nests, including desert monitor (Varanus griseus; $n=26$ ) and fox (Vulpes vulpes or Vulpes corsac; $n=4$ ). Nests were more susceptible to desert monitor predation later in the season, when tested in univariate models in RMark (coding outcome as: $1=$ desert monitor predation, $0=$ success or another cause of failure; $\triangle \mathrm{AIC}=9.5, \Delta \mathrm{AIC}=3.6$ on removal of date $^{2}$ and then date, respectively). Similarly, the probability of nest failure from other causes changed through the season, but only the quadratic term of date was supported (outcome as: $1=$ all causes of failure other than desert monitor, $0=$ success or desert monitor predation, date ${ }^{2}: \Delta \mathrm{AIC}=3.1$, date: $\triangle \mathrm{AIC}=-2.0)$. Two clutches were apparently taken by shepherds, three were trampled by sheep and two held undeveloped eggs (Table 2).

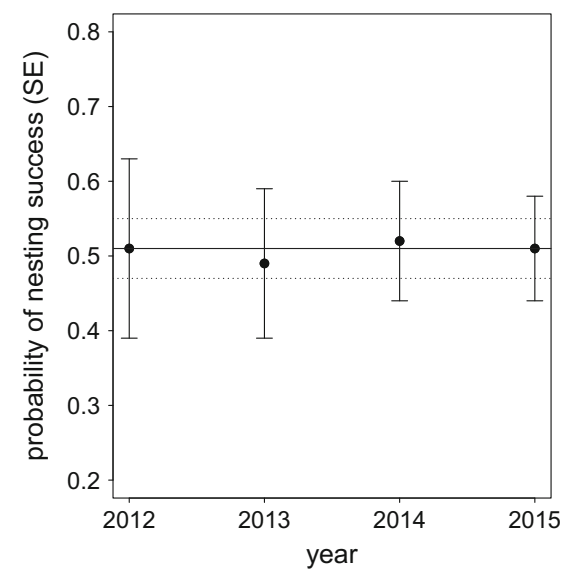

Fig. 3 Inter-annual variation of nest success in Asian houbara Chlamydotis macqueenii in the Kyzylkum Desert, Uzbekistan (vertical bars show standard error, horizontal line represents mean nesting success across 4 years, dotted lines are SE of the mean)

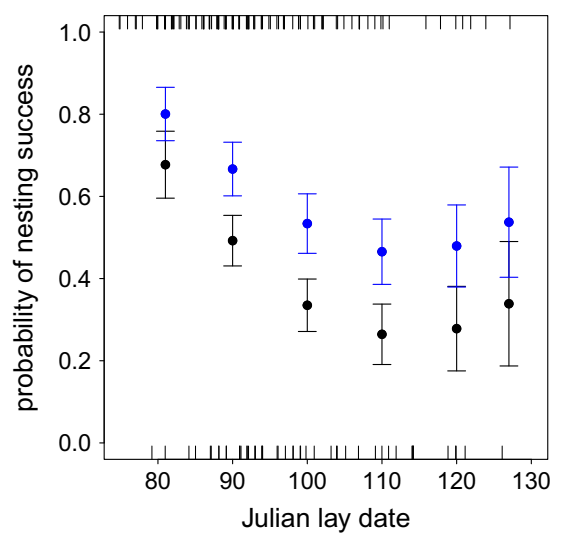

Fig. 4 Estimated variation of nest hatching success (vertical bars are SEs) with the additive effects of first egg lay date and mean shrub height around the nest (50-m radius) for Asian houbara Chlamydotis macqueenii in the Kyzylkum Desert, Uzbekistan. Blue dots are the upper, $35.8 \mathrm{~cm}$, and black are the lower, $26.5 \mathrm{~cm}$, quartiles of the shrub height distribution. Observed outcomes are shown as jitter on the top and bottom axes, where 0 is failed to hatch and 1 is hatched. Julian lay date is number of days from 1 January

Video in 2014 recorded sheep flocks in the proximity on 24 occasions at five of nine nests, with females leaving when sheep approached in 11/24 instances, yielding a mean disturbance rate at these nests of 0.12 day $^{-1}(\mathrm{SE} \pm 0.03)$ and across the nine nests of 0.09 day $^{-1}(\mathrm{SE} \pm 0.02)$ (Online resources, Section 3). Females appeared to stay off the nest longer $(\triangle \mathrm{AIC}=18.8$ on variable removal, controlling for nest ID as random effect) after sheep disturbance $(n=11$, mean $\pm \mathrm{SD}=46.2 \pm 26.2 \mathrm{~min}$ ) than after other absences for the same five nests ( $n=296$, mean $\pm \mathrm{SD}=22.1 \pm 25.0 \mathrm{~min}$ ), possibly because sheep flocks take some time to pass through an area.

Probability of houbara nest success was substantially greater $($ mean $\pm \mathrm{SE}=65.5 \pm 6.5 \%)$ with taller mean shrub height (upper quartile mean $=35.8 \mathrm{~cm}$ ) than with lower mean shrub height (lower quartile mean $=26.4 \mathrm{~cm}$; mean nest success

Table 2 Causes of nest failure and number of successful nests for Asian houbara Chlamydotis macqueenii in the Kyzylkum Desert, Uzbekistan; $n=174$ nests with known outcome monitored during 2012-2015, separately for nests laid before and after the median laying date (2 April)

\begin{tabular}{|c|c|c|c|}
\hline & Before median & After median & Total \\
\hline Successful nests & 58 & 57 & 115 \\
\hline \multicolumn{4}{|l|}{ Causes of nest failure } \\
\hline Total failed & 18 & 41 & 59 \\
\hline Desert monitor & 6 & 20 & 26 \\
\hline Fox sp. & 1 & 3 & 4 \\
\hline Unconfirmed predator & 2 & 9 & 11 \\
\hline Shepherd & 1 & 1 & 2 \\
\hline Trampled by sheep & 3 & 0 & 3 \\
\hline Failed to hatch & 0 & 2 & 2 \\
\hline Failed (reason unknown) & 5 & 6 & 11 \\
\hline
\end{tabular}


$\pm \mathrm{SE}=47.3 \pm 6.0 \%$ ), the effect being strongly supported with an RVI well beyond the $95 \%$ null interval and CIs not spanning zero (Figs. 2b and 4). In contrast, nest success was not affected by sheep density, topographic rugosity, shrub density or shrub composition (i.e. vegetation MDS2), with CIs spanning zero and RVIs within $95 \%$ null interval (Fig. 2b). The alternative MMI incorporating shrub assemblage, instead of shrub height, showed no support for any of the predictors modelled.

\section{Hatchability}

Hatchability was high, with $87.5 \%$ (95 \% CI 83.1-91.8\%) probability of an egg in a successful nest hatching $(n=196$ chicks hatched from 224 eggs; $n=68$ nests suitable for analysis). Controlling for female ID as a random effect in univariate tests indicated no support for an effect of laydate ${ }^{2}$ $(\triangle \mathrm{AIC}=0.3)$ or laydate $(\Delta \mathrm{AIC}=1.6)$ on hatchability, so laydate was not included in MMI as a candidate effect. No support for influence of any land-use or habitat variables on hatchability (and thus embryo survival) was found (CIs spanning zero; RVI within $95 \%$ null interval) (Fig. 2c), with alternative MMI models incorporating shrub assemblage giving similar results.

\section{Discussion}

Asian houbara nest productivity did not vary between three shrub assemblages or with moderate levels of pastoralism activity and infrastructure, but nests placed within taller vegetation experienced greater success. Daily nest survival decreased with season, probably owing to the emergence of monitor lizards, but also showed some recovery at the end of the nesting season, perhaps as the activity of these predators declined. Mean nest success of $51.4 \%$ (95\% CI 42.4$60.4 \%$ ), estimated from 163 nests over 4 years, was similar to a 3-year mean from China (mean $=58.8 \%, \mathrm{SD}=27.0$, $n=45$; Combreau et al. 2002) and a 5-year study in Israel (mean $=47 \%, n=12$; Lavee 1988). We are unable to compare this level of nest success with that of other bustard species owing to a lack of similar reliable data on these cryptic birds.

\section{Nest predation}

Predation was the main cause of nest failure, accounting for at least $70 \%$ of all failed nests and $85 \%$ of those for which the cause was considered known. In contrast, removal of eggs by shepherds or trampling by sheep accounted for $11 \%$ of all nest failures and for $10 \%$ of those where the cause was known, and sheep density had no detectable effect on nest success. Predation by desert monitors contributed $54 \%$ of all nest failures for which the cause was considered known and
$63 \%$ of known predation. Although predation of houbara nests by this species has been noted previously (Gubin 2004; Launay et al. 1997), predation by foxes and corvids is reported more frequently (Combreau and Launay 1999; Combreau et al. 2002; Gubin 2004; Lavee 1988). In our study, only $10 \%$ of known predation was attributable to foxes, and even assuming that foxes may have contributed disproportionately to nests affected by 'unknown' predators (a further $27 \%$ of known predation), monitors remain the primary nest predator. However, low rodent abundance throughout this study may have depressed fox numbers.

Species responsible for nest predation were mostly inferred from tracks and signs, except for 10 predations by desert monitors recorded on nest cameras. Desert monitors often left claw/tail marks and either emptied the nest (if all eggs were swallowed unbroken) or left some yolk and eggshell fragments (if eggs broke during swallowing). Foxes, in contrast, are unlikely to leave many tracks by the nest and often carry the eggs away to eat or hide, so there may be no remains close to the scrape (MK, personal observation; Combreau et al. 2002). Foxes were probably responsible for some of the unattributed nest predation (Online resources, Section 3); however, even if all unattributed predation and all unknown-cause failures were attributed to foxes (inevitably a considerable over-estimate), predation by foxes would still be below that by desert monitors (37.2 and $44.1 \%$ of all failures, respectively).

In contrast to the lack of inter-annual variation in nest success in our study, in China, large variation between years was attributed to fluctuation in predator densities (Combreau et al. 2002). Such variability is expected in regions where populations of rodents such as great gerbil Rhombomys opimus (a staple prey of Central Asian mammalian predators) exhibit pronounced temporal fluctuations (Gauthier et al. 2004; Linné Kausrud et al. 2007; Salek et al. 2004). Rodent numbers (particularly gerbils) fluctuate in Bukhara (Shenbrot and Rogovin 1995), but following a peak in 2010, the abundance of both rodents and mammalian carnivores remained low in all four study years (MK, unpublished data). However, the substantial contribution of monitors to nest predation may dampen any inter-annual variation in nest productivity arising from future changes in fox numbers following rodent outbreak years.

Predator control is often advocated as a conservation measure for vulnerable bird species and can enhance both breeding productivity and subsequent population size (Smith et al. 2010). However, sustained removal of predators poses both ethical and practical problems. Landscape-scale extirpation or substantial suppression of desert monitor numbers may have potential unforeseen effects, e.g. increasing rodent prey and thus generalist predator numbers. Moreover, the species is persecuted widely for use in traditional medicine and has an unfavourable conservation status in several countries (Bergin 
and Nijman 2014; Grigoryants 2010; Kovshar 1996). We oppose the control of desert monitors as a measure to increase houbara numbers.

\section{Effect of season}

Early clutches had higher chances of survival owing to the later emergence of desert monitors $(n=58$ monitor observations, first date $=15$ April, median date $=13$ May), with chances of nest success decreasing by almost $50 \%$ by the end of the season, coinciding with the peak of monitor activity in May-June (Pianka et al. 2004). As the number of active nests diminishes towards the end of the breeding period, finding new nests by tracking becomes extremely difficult, with smaller sample sizes in the first 3 years of study limiting our ability to detect any increase in late-season nest survival. However, in 2015, substantially more late-season nests were found (mostly nests of PTT-tagged females), increasing sample size sufficiently to detect a subsequent (approx. $7 \%$ ) partial recovery in nest survival, potentially attributable to seasonal phenology of monitors.

\section{Habitat effects}

Higher nest success in areas with taller mean shrub vegetation (mean height $\pm \mathrm{SD}=32.6 \pm 8.2$ and $29.1 \pm 7.4 \mathrm{~cm}$ for successful and failed nests, respectively; Fig. 4) suggests that females may benefit from concealment by shrubs. Incubating females often react to an approaching threat by running away fast, keeping head and neck low (observations from nest cameras). In slightly taller vegetation, these large birds may have a greater chance of fleeing the nest undetected by a predator, analogous to the concealment effect of small-scale topographic rugosity for nesting great bustard Otis tarda (Magana et al. 2010). We found no effect of topographic rugosity on houbara nest success, perhaps because this relatively coarse measure (30-m horizontal resolution, examined over a radius of $100 \mathrm{~m}$ ) failed to capture smaller-scale topographic cover near nests. Another explanation is that hillocks and elevations probably do not provide much additional concealment against major predators for incubating females. Foxes, being mostly nocturnal, rely on smell or sound when foraging, while in shrubby desert, diurnal monitor lizards, although thought to have excellent vision like other Varanus (Pianka et al. 2004), seem more likely to detect a nest or a female at relatively close range, so nesting in a depression between hillocks or in a flat area may have similar costs for nest survival.

We found no difference in nest success, clutch size or hatchability between the three shrub assemblages considered. In contrast, male abundance within the same study area varied between these assemblages (MK, unpublished data), being substantially higher in $S$. rigida than in S. arbuscula and Astragalus habitats. Higher male numbers in $S$. rigida habitat are likely to be related to better conditions for display visibility over large distances in this flatter habitat, dominated by short and dwarf shrubs. For the habitats assessed here, it seems that, as long as females can find localised areas with suitable taller shrubs to camouflage their movements, nests have greater chance of success irrespective of shrub species composition. Breeding male houbara, by contrast, occur in higher abundances where vegetation is shorter (Koshkin et al. 2014, 2016), indicating the importance of landscape heterogeneity for the species. Such variation is provided by local topographical relief within each of the widely distributed plant assemblages studied here.

Although few nests were found in areas where clay substrate dominated, we attribute this to difficulties tracking on these substrates and do not infer a difference in habitat preference or densities of nesting females. Moreover, male densities in some clay areas were found to be higher than in areas with consolidated sand (Koshkin et al. 2016), which suggests high local availability of breeding females; densities of main predators do not seem to depend on substrate (personal observation). We therefore have no reason to expect a lower density of nesting females in clay-dominated areas.

\section{Land-use effects}

Absence of any detectable effects of livestock density on houbara nest success or hatchability in successful nests agrees with Johnson et al. (2012), who found no effect of different stocking rates and only a minor effect of trampling on nest success for a range of ground-nesting passerine species in dry savanna in Oregon, USA. However, in Israel, high densities of livestock (at mean density of 80 individuals $\mathrm{km}^{-2}$ ) were considered the main cause of poor nest success in Asian houbara (Lavee 1988), based on observations of sheep flocks displacing incubating females from nests, potentially exposing eggs to unfavourable temperatures and predation. Contrasts may arise owing to differences in grazing systems among regions, including density, seasonality and duration of grazing, as well as cultural factors (e.g. dog use, egg collection and subsistence hunting by shepherds). We also acknowledge the lack of samples of nests from areas with the most extreme $\left(>80\right.$ individuals $\mathrm{km}^{-2}$ ) sheep density where our failure to locate any nests was due to difficulties in tracking over sand heavily disturbed by sheep and also perhaps due to lower nesting densities there. Human nest-robbing appears to be a minor factor in the Kyzylkum.

Video monitoring of a sample of nests disturbed at least once by sheep flocks (often accompanied by shepherds) suggested that displacement rates were low even for this subset of nests. Nevertheless, females were absent for twice as long compared to other causes (displaced by cars, other houbara or unknown reasons) (Online resources, Section 3), potentially exposing clutches to predators and uncontrolled 
temperatures for longer periods. This and the fact that all three nests trampled in our study were located in areas of high sheep density ( $>50$ individuals $\mathrm{km}^{-2}$ ) suggest that extreme livestock densities could indeed compromise houbara nest success. Further telemetry data may reveal whether nesting females avoid very high sheep densities when selecting nest sites, as the presence of sheep flocks prior to houbara arrival provides a potential cue for settlement. In the current study, we did not examine habitat or livestock influences on chick performance after leaving the nest; however, given the lack of any appreciable livestock impact on habitat structure (Koshkin et al. 2014), we do not envisage mechanisms by which livestock would affect habitat suitability for chicks.

\section{Implications and further research}

Nest success was unaffected by variation in shrub species composition or livestock density, suggesting that the Asian houbara is a versatile, adaptable occupant of a range of arid habitats.

Initiation of clutches within 1 or 2 weeks of return to the Kyzylkum, at a time when weather conditions are generally wintry, desert plants still dormant and evidence of invertebrate life hard to find (personal observation), suggests that females must retain substantial reserves after their migration. This quick onset of breeding may be a strategy to avoid incubation during the period of peak monitor activity, when nest success suffers a $50 \%$ reduction, but females may also be under pressure to complete nesting well ahead of maximum summer temperatures (July-August), so that chicks optimise benefits from the spring flush (May-June) of resource availability (Daan et al. 1989). The lack of difference in egg volume between years is in contrast to the observed difference in chick weight (RJB, unpublished data), suggesting that egg productivity depends on resources in wintering or passage sites, rather than foraging conditions on the breeding grounds. Conditions and habitat suitability in wintering and staging areas may therefore have important carry-over effects for productivity as well as for winter survival.

We found no difference in houbara clutch size or nest success among habitats and with different livestock densities. In theory, for species with non-exclusive home ranges, ideal free settlement could allow compensatory density dependence, masking underlying differences in habitat quality and productivity (Dolman 2012), but we cannot envisage a mechanism for strong density-dependent houbara breeding productivity. Prey depletion is unlikely at the scale of female home range, and predator aggregation in response to landscape-scale variation in houbara density is unlikely. Consequently, we consider that this range of habitats provides a broadly similar quality for nesting females. The protection of extensive halophytic landscapes is therefore indicated. The similar levels of nest productivity in S. arbuscula, S. rigida and Astragalus habitats suggest that all three are key and should be protected against further habitat loss or infrastructure development (pipelines, powerlines, roads). Although we were unable to examine nest success in Calligonum habitat, few houbara are encountered in this habitat during the breeding season (Gubin 2004; Koshkin et al. 2014). The role of Artemisia-dominated habitat, insufficiently sampled in this study, needs further examination. Although we found no differences in nest productivity, we did not test whether rates of juvenile survival (which also contribute to overall breeding productivity) differ between habitats.

We have explored whether in situ measures may be available to enhance productivity, in order to offset hunting mortality at least partially, and thereby reduce the need for sustained large-scale release of captive-bred birds, with its associated risks. Our results suggest that Asian houbara in the southern Kyzylkum have good nest success while tolerating current levels of sheep grazing and human disturbance. However, as nest productivity was similar across habitat and land-use gradients, this study provides no obvious mechanisms to enhance productivity of free-living birds. From this, we are forced to conclude that the scale of anthropogenic mortality during migration and winter needs to be reduced by controlling poaching and regulating hunting (Combreau et al. 2005; Burnside et al. 2016) in order to reduce the scale of and need for captive-bred releases and to render hunting sustainable in the long term.

Acknowledgments This study was funded by the Ahmed bin Zayed Charitable Foundation. We are grateful to the State Committee for Nature Conservation of the Republic of Uzbekistan for permission to conduct the study and the Emirates Bird Breeding Center for Conservation (EBBCC) for collaboration and logistical support. We warmly thank Elizabeth Grayshon, João Guilherme, David Hodkinson, Erasil Khaitov, Judit Mateos-Herrero, Dave Showler, Andrew Taylor and Vladimir Terentyev for their contributions to data collection. We are most grateful to Olivier Combreau for his useful advice and to Loïc A. Hardouin and two anonymous referees for very helpful comments on an earlier version of this paper.

Open Access This article is distributed under the terms of the Creative Commons Attribution 4.0 International License (http:// creativecommons.org/licenses/by/4.0/), which permits unrestricted use, distribution, and reproduction in any medium, provided you give appropriate credit to the original author(s) and the source, provide a link to the Creative Commons license, and indicate if changes were made.

\section{References}

Aebischer NJ (1999) Multi-way comparisons and generalized linear models of nest success: extensions of the Mayfield method. Bird Stud 46:S22-S31

Aghanajafizadeh S, Hemami MR, Heydari F (2012) Nest-site selection by the Asian houbara bustard, Chlamydotis macqueenii, in the steppe of Harat, Iran (Aves: Otidae). Zool Middle East 57:11-18. doi:10.1080/09397140.2012.10648958 
Barton K (2013) MuMIn: multi-model inference. R package version 1.15.1, URL http://cran.r-project.org/web/packages/MuMIn/index. html

Bergin D, Nijman V (2014) Open, unregulated trade in wildlife in Morocco's markets. TRAFFIC Bull 26:65-70

BirdLife International (2014) Review of the global conservation status of the Asian houbara bustard Chlamydotis macqueenii. Report to the Convention on Migratory Species Office - Abu Dhabi. BirdLife International, Cambridge

BirdLife International (2015) Species factsheet: Chlamydotis macqueenii. Downloaded from http://www.birdlife.org. Accessed 22 Aug 2015

Boughey KL, Lake IR, Haysom KA, Dolman PM (2011) Effects of landscape-scale broadleaved woodland configuration and extent on roost location for six bat species across the UK. Biol Conserv 144: 2300-2310. doi:10.1016/j.biocon.2011.06.008

Burnham KP, Anderson DR (eds) (2002) Model selection and multimodel inference. A practical information-theoretic approach. Springer, New York

Burnside RJ, Collar NJ, Scotland KM, Dolman PM (2016) Survival rates of captive-bred Asian houbara Chlamydotis macqueenii in a hunted migratory population. Ibis 158:353-361. doi:10.1111/ibi.12349

Carrascal LM, Palomino D, Seoane J, Alonso CL (2008) Habitat use and population density of the houbara bustard Chlamydotis undulata in Fuerteventura (Canary Islands). Afr J Ecol 46:291-302. doi:10. 1111/j.1365-2028.2008.00971.x

Chargé R, Sorci G, Saint Jalme M, Lesobre L, Hingrat Y, Lacroix F, Teplitsky C (2014) Does recognized genetic management in supportive breeding prevent genetic changes in life-history traits? Evol Appl 7:521-532. doi:10.1111/eva.12150

Clarke KR (1993) Nonparametric multivariate analyses of change in community structure. Aust J Ecol 18:117-143. doi:10.1111/j.14429993.1993.tb00438.x

Combreau O, Launay F (1999) An estimation of the nesting success in a houbara bustard Chlamydotis undulata macqueenii population in Kazakhstan. Sandgrouse 21:171-175

Combreau O, Qiao J, Lawrence M, Gao X, Yao J, Yang W, Launay F (2002) Breeding success in a houbara bustard Chlamydotis [undulata] macqueenii population on the eastern fringe of the Jungar Basin, People's Republic of China. Ibis 144:E45-E56. doi: 10.1046/j.1474-919X.2002.00054.X

Combreau O, Launay F, Lawrence M (2005) Progress, challenges and perspective in houbara bustard conservation in Asia. In: Bota G, Morales MB, Mañosa S, Camprodon J (eds) Ecology and conservation of steppe-land birds. Lynx Editions, Barcelona

Crawley MJ (2007) The R book. Wiley, Chichester

Daan S, Dijkstra C, Drent R, Meijer T (1989) Food supply and the annual timing of avian reproduction. In: Acta XIX Congr. Int. Omithol., Ottawa, pp 392-407

Dinsmore SJ, White GC, Knopf FL (2002) Advanced techniques for modelling avian nest survival. Ecology 83:3476-3488. doi:10. 1890/0012-9658(2002)083[3476:atfman]2.0.co;2

Dolman PM (2012) Mechanisms and processes underlying landscape structure effects on bird populations. In: Fuller RJ (ed) Birds and habitat: relationships in changing landscapes. Cambridge University Press, Cambridge

Dolman PM, Collar NJ, Scotland KM, Burnside RJ (2015) Ark or park: the need to predict relative effectiveness of ex situ and in situ conservation before attempting captive breeding. J Appl Ecol 52:841850. doi:10.1111/1365-2664.12449

Frankham R (2008) Genetic adaptation to captivity in species conservation programs. Mol Ecol 17:325-333. doi:10.1111/j.1365-294X. 2007.03399.x

Gauthier G, Bêty J, Giroux J-F, Rochefort L (2004) Trophic interactions in a high Arctic Snow Goose colony. Integr Comp Biol 44:119-129. doi:10.1093/icb/44.2.119
Gintzburger G, Toderich KN, Mardonov BK, Mahmudov MM (2003) Rangelands of the arid and semi-arid zones in Uzbekistan. CIRAD, ICARDA, Paris

Grigoryants AA (ed) (2010) Red data book of Uzbekistan vol 2. Chinor ENK, Tashkent

Gubin BM (2004) Drofa-krasotka (houbara bustard) (in Russian). Kolor, Almaty

Hardouin LA, Hingrat Y, Nevoux M, Lacroix F, Robert A (2015) Survival and movement of translocated houbara bustards in a mixed conservation area. Anim Conserv 18(5):461-470. doi:10.1111/acv. 12196

Hingrat Y, Saint Jalme M, Chalah T, Orhant N, Lacroix F (2008) Environmental and social constraints on breeding site selection. Does the exploded-lek and hotspot model apply to the houbara bustard Chlamydotis undulata undulata? J Avian Biol 39:393-404. doi: 10.1111/j.2008.0908-8857.03994.x

Hoyt DF (1979) Practical methods of estimating volume and fresh weight of birds' eggs. Auk 96:73-77

Islam MZ, Basheer MP, Shah MS, al Subai H, Boug A (2012) Captivebreeding and reintroduction of the Asian houbara bustard Chlamydotis macqueenii in the Kingdom of Saudi Arabia: lessons learned. Int Zoo News 59:338-360

Johnson TN, Kennedy PL, Etterson MA (2012) Nest success and causespecific nest failure of grassland passerines breeding in prairie grazed by livestock. J Wildl Manag 76:1607-1616. doi:10.1002/ jwmg. 437

Kerven C, Shanbaev K, Alimaev J, Smailov A, Smailov K (2006) Livestock mobility and degradation in Kazakhstan's semi-arid rangelands. In: Behnke R (ed) Socio-economic causes and consequences of desertification in Central Asia. Nato Science for Peace and Security Series C-Environmental Security. Springer, Dordrecht, pp 113-140. doi:10.1007/978-1-4020-8544-4 6

Koshkin MA, Collar NJ, Dolman PM (2014) Do sheep affect distribution and habitat of Asian houbara Chlamydotis macqueenii? J Arid Environ 103:53-62. doi:10.1016/j.jaridenv.2014.01.002

Koshkin MA, Burnside RJ, Collar NJ, Guilherme JL, Showler DA, Dolman PM (2016) Effects of habitat and land-use on breedingseason density of male Asian houbara Chlamydotis macqueenii. J Ornithol. doi:10.1007/s10336-015-1320-4

Kovshar AF (ed) (1996) Red data book of Kazakhstan. Almaty

Laake JL (2013) RMark: an R interface for analysis of capture-recapture data with MARK. AFSC Processed Rep 2013-01, 25p. Alaska Fish. Sci. Cent., NOAA, Natl. Mar. Fish. Serv., 7600 Sand Point Way NE, Seattle WA 98115

Launay F, Loughland R, Mukhina EA (1997) Preliminary observations of the incubation and covey behaviour of houbara bustard Chlamydotis undulata macqueeni. Sandgrouse 19:51-55

Lavee D (1988) Why is the houbara Chlamydotis undulata macqueenii still an endangered species in Israel? Biol Conserv 45:47-54

Le Cuziat J, Lacroix F, Roche P, Vidal E, Medail F, Orhant N, Beranger PM (2005a) Landscape and human influences on the distribution of the endangered North African houbara bustard (Chlamydotis undulata undulata) in eastern Morocco. Anim Conserv 8:143152. doi:10.1017/s1367943005001903

Le Cuziat J, Vidal E, Roche P, Lacroix F (2005b) Human activities affect the potential distribution of the houbara bustard Chlamydotis undulata undulata. Ardeola 52:21-30

Linné Kausrud K et al (2007) Climatically driven synchrony of gerbil populations allows large-scale plague outbreaks. P Roy Soc B-Biol Sci 274:1963-1969. doi:10.1098/rspb.2007.0568

Magana M, Alonso JC, Martin CA, Bautista LM, Martin B (2010) Nestsite selection by Great Bustards Otis tarda suggests a trade-off between concealment and visibility. Ibis 152:77-89. doi:10.1111/j. 1474-919X.2009.00976.x

Mallord JW, Dolman PM, Brown A, Sutherland WJ (2007) Nest-site characteristics of Woodlarks Lullula arborea breeding on heathlands 
in southern England: are there consequences for nest survival and productivity? Bird Stud 54:307-314. doi:10.1080/ 00063650709461490

Mayfield H (1961) Nesting success calculated from exposure. Wilson Bull 73:255-261

Mayfield H (1975) Suggestions for calculating nesting success. Wilson Bull 87:456-466

Peet RK, Roberts DW (2013) Classification of natural and semi-natural vegetation. In: Vegetation ecology. Wiley, pp 28-70. doi:10.1002/ 9781118452592.ch2

Pianka ER, King D, King RA (eds) (2004) Varanoid lizards of the world. Indiana University Press, Bloomington

R Core Team (2013) R: a language and environment for statistical computing. R Foundation for Statistical Computing, Vienna, url: http:// www.R-project.org/

Richardson TW, Gardali T, Jenkins SH (2009) Review and meta-analysis of camera effects on avian nest success. J Wildl Manag 73:287-293. doi:10.2193/2007-566

Riou S, Judas J, Lawrence M, Pole S, Combreau O (2011) A 10-year assessment of Asian houbara bustard populations: trends in Kazakhstan reveal important regional differences. Bird Conserv Int 21:134-141. doi:10.1017/s0959270910000377

Robinson TP, Franceschini G, Wint W (2007) The Food and Agriculture Organization's gridded livestock of the world. Vet Ital 43:745-751

Salek M, Svobodova J, Bejcek V, Albrecht T (2004) Predation on artificial nests in relation to the numbers of small mammals in the Krusne hory Mts, the Czech Republic. Folia Zool 53:312-318
Shenbrot GI, Rogovin KA (1995) Temporal variation in spatial organization of a rodent community in the southwestern Kyzylkum desert (Middle Asia). Ecography 18:370-383. doi:10.1111/j.1600-0587. 1995.tb00140.x

Smith RK, Pullin AS, Stewart GB, Sutherland WJ (2010) Effectiveness of predator removal for enhancing bird populations. Conserv Biol 24:820-829. doi:10.1111/j.1523-1739.2009.01421.x

Snyder NFR, Derrickson SR, Beissinger SR, Wiley JW, Smith TB, Toone WD, Miller B (1996) Limitations of captive breeding in endangered species recovery. Conserv Biol 10:338-348. doi:10.1046/j.15231739.1996.10020338.x

Tourenq C et al (2005) Alarming houbara bustard population trends in Asia. Biol Conserv 121:1-8. doi:10.1016/j.biocon.2004.03.031

Waber K, Spencer J, Dolman PM (2013) Achieving landscape-scale deer management for biodiversity conservation: the need to consider sources and sinks. J Wildl Manag 77:726-736. doi:10.1002/jwmg. 530

WAM (2014) Two thousand captive-bred Asian houbara released in Kazakhstan. http://www.wam.ae/en/news/general-emiratesinternational/1395242971839.html

Williams SE, Hoffman EA (2009) Minimizing genetic adaptation in captive breeding programs: a review. Biol Conserv 142:2388-2400. doi:10.1016/j.biocon.2009.05.034

Yang WK, Qiao JF, Combreau O, Gao XY, Zhong WQ (2003) Breeding habitat selection by the houbara bustard Chlamydotis [undulata] macqueenii in Mori, Xinjiang, China. Zool Stud 42:470-475 